\title{
Management of achalasia
}

This article was published in the following Dove Press journal:

Clinical and Experimental Gastroenterology

23 February 201I

Number of times this article has been viewed

\section{Luca Dughera' \\ Michele Chiaverina' \\ Luca Cacciotella' \\ Fabio Cisarò ${ }^{2}$}

'Internal Medicine, Motility and Endoscopy Unit, ${ }^{2}$ Gastroenterology and Hepatology Unit, Department of Medicine, San Giovanni Battista Hospital, Torino, Italy
Correspondence: Luca Dughera Motility and Endoscopy Unit, San Giovanni Battista Hospital, Via Genova, 3 I0I2I Torino, Italy

$\mathrm{Tel}+39$ II 6336762

Fax +39|| 66| 4652

Email luca.dughera@libero.it
Abstract: Several theories on the etiology and pathophysiology of achalasia have been reported but, to date, it is widely accepted that loss of peristalsis and absence of swallow-induced relaxation of the lower esophageal sphincter are the main functional abnormalities. Treatment of achalasia often aims to alleviate the symptoms of achalasia and not to correct the underlying disorder. Medical therapy has poor efficacy, so patients who are good surgical candidates should be offered either laparoscopic myotomy or pneumatic balloon dilatation. Their own preference should be included in the decision-making process, and treatment should meet the local expertise with these procedures. Laparoscopic surgical esophagomyotomy is a safe and effective modality. It can be considered as initial management or as secondary treatment if the patient does not respond to less invasive modalities. Pneumatic dilatation has proven to be a safe, effective, and durable modality of treatment when performed by experienced individuals, and appears to be the most cost-effective alternative. For patients with multiple comorbidities and for elderly patients, who are not good surgical candidates, endoscopic injection of botulinum toxin should be considered a safe and effective procedure. However, its positive effect diminishes over time, and the need for multiple repeated sessions must be taken into consideration. In the management of patients with achalasia, nutritional aspects play an important role. When lifestyle changes are insufficient, it is necessary to proceed to percutaneous gastrostomy under radiological guidance. In the future, intraluminal myotomy or endoscopic mucosectomy will possibly be an option. Further studies are needed to investigate the role of immunosuppressive therapies in those cases in which an autoimmune etiology is suspected.

Keywords: achalasia, esophageal sphincter, botulinum toxin A, dilation

\section{Introduction}

Achalasia is a rare motor disorder of the esophagus and lower esophageal sphincter. More specifically, it a neuromuscular disorder characterized by degenerative changes of the myenteric plexus leading to a selective loss of inhibitory nerve endings. Irreversible disruption of peristaltic contractions and impaired relaxation of the lower esophageal sphincter in response to deglutition are the consequences of this damage. ${ }^{1}$

Primary idiopathic achalasia is a quite rare disease, with an incidence of approximately $1 / 100,000 /$ year and a prevalence rate of 10/100,000. Primary achalasia in children is part of the Allgrove's and Alport's syndromes, and is more frequent in Down's syndrome. ${ }^{2}$

Secondary achalasia shares clinical features with primary achalasia, but there is always an identifiable cause. Worldwide, the most common cause of secondary achalasia is protozoal infection by Trypanosoma cruzi, found in Central and South America. 
An association with Class II human leukocyte antigens ${ }^{3,4}$ and some viral infections ${ }^{5}$ has been described. An autoimmune pathogenesis in achalasia has been sustained due to the description of antimyenteric neuron antibodies in a subset of patients. ${ }^{6}$

When achalasia is caused by infiltration of the lower esophageal sphincter, by malignancy, or by diseases such as amyloidosis, or as a result of a paraneoplastic syndrome, the term pseudoachalasia is used. Malignancies lead to pseudoachalasia most commonly by direct invasion into the esophagus and lower esophageal sphincter (most commonly gastroesophageal adenocarcinoma, but also oat cell carcinoma, bronchogenic carcinoma, esophageal squamous cell carcinoma, or lymphoma) or by a paraneoplastic phenomenon without cancerous involvement of the lower esophageal sphincter.

An achalasic picture may be mimicked by complications of surgery involving the gastroesophageal junction that may lead to impaired passage of esophageal contents into the stomach, and esophageal dilatation, such as fundoplication, gastric banding, and as a result of injury to the vagus nerve. ${ }^{7}$

From the clinical point of view, achalasia is a progressive disease that presents with symptoms of dysphagia both for liquid and solid foods, chest pain and regurgitation of undigested foods that occurs during meals, shortly thereafter or hours later when the patient changes into the recumbent position. More subtle symptoms include slowing of the speed of eating and stretching or side-to side movement, as well as walking around after meals to accomplish bolus passage through the nonperistaltic esophagus and across the hypertonic lower esophageal sphincter. Aspiration of food from the esophagus may lead to pneumonia. Loss of weight and malnutrition are uncommon, but they may occur in advanced disease and in elderly patients.

All patients with dysphagia should undergo upper gastrointestinal endoscopy and radiology to rule out anatomic lesions as the first diagnostic step. ${ }^{8}$ Diagnostic accuracy is provided only by esophageal manometric studies in over $96 \%$ of cases showing a typical pattern both in primary achalasia and pseudoachalasia. ${ }^{9}$

The treatment of achalasia has traditionally relied on a surgical approach. The advent of minimally invasive surgery with a shorter hospital stay, reduced morbidity, and faster return to daily activity, makes this option even more attractive. In contrast, there is evidence that some medical and nonsurgical strategies may be of benefit in many patients with this disorder. This review summarizes the current knowledge and future perspectives for the management of achalasia.

\section{Pathophysiology}

Although a full description of the complex and still poorly understood mechanisms that underlie achalasia are not the aim of this review, a brief summary of these is useful in order to comprehend the rationale of different treatment options.

The hallmark of achalasia is failure of complete lower esophageal sphincter relaxation. The mechanism of lower esophageal sphincter relaxation is complex, requiring the coordinated interaction of nerves, smooth muscle, interstitial cells of Cajal (ICC), and hormones. Coordinated peristaltic waves that move the food bolus through the distal esophagus depend on excitatory and inhibitory input from local enteric reflexes that originate in the enteric nervous plexus and from extrinsic parasympathetic nerves. The peristaltic reflex involves both cholinergic and peptide excitatory neurotransmission, resulting in contraction of both circular and longitudinal muscle proximal to the bolus, preceded by aboral relaxation ahead of the bolus. While acetylcholine mediates the majority of the neurotransmission between the vagus and intrinsic neurons, it appears that more than one neurotransmitter plays a role between the inhibitory myenteric neuron, ICC, and smooth muscle. A variety of mediators have been proposed, but the main inhibitory factor is nitric oxide. ${ }^{10,11}$ Thus, the nitric oxidereleasing inhibitory neurons are the target in idiopathic achalasia. The triggering event that leads to ganglion cell degeneration in achalasia is still unclear, but loss of nitric oxide-secreting neurons leads to an imbalance between the excitatory and inhibitory neurons of the myenteric plexus, producing irreversible manometric changes in such patients. ${ }^{12,13}$

Intramuscular ICC have been clearly identified in the lower esophageal sphincter. ${ }^{14}$ ICC in the gastrointestinal tract have several different functions, serving as pacemakers, as generators of a smooth muscle hyperpolarizing factor, ${ }^{15}$ as mechanic sensors, ${ }^{16}$ and as mediators of neurotransmission. ${ }^{17}$ Together with the loss of myenteric neurons, a reduction in the number of ICC in the lower esophageal sphincter region has also been reported in idiopathic achalasia. ${ }^{18,19}$ While ICC have an established role in mediating nitrogen and cholinergic neurotransmission in other regions of the gastrointestinal tract, defining the role of ICC in normal lower esophageal sphincter function will require further work. 


\section{Treatment options}

Treatment of achalasia focuses on relaxation or mechanical disruption of the lower esophageal sphincter. Achalasia is a fairly rare disease, so there are few randomized and controlled clinical trials to define the optimal strategy to treat it. Safety, effectiveness, and durability of current treatment options vary widely.

The progression of achalasia is due primarily to the resistance to the passage of bolus through the poorly relaxing and opening lower esophageal sphincter. If achalasia is left untreated, a dilated esophagus with severe bolus transit impairment will develop, and that condition signals high risk for aspiration pneumonia or perforation. Therefore, the goal in the management of achalasia is an early diagnosis and treatment before reaching this end-stage phase, when surgery becomes mandatory, but usually with a poor outcome. An overview of the current therapeutic options in achalasia is summarized in Table 1.

\section{Pharmacologic therapy}

Pharmacologic therapy for the treatment of achalasia would be preferable to the more invasive options for treatment. Unfortunately, such treatment does not eliminate the underlying disease process, but only temporarily leads to lower esophageal sphincter relaxation and may improve symptoms. Nowadays, medical therapy includes nitrates, calcium channel blockers, and nitric oxide donors in an attempt to either facilitate lower esophageal sphincter relaxation and/or enhance esophageal peristalsis.

Calcium channel blockers and nitrates, usually taken 30-60 minutes before meals, have traditionally been the focus of pharmacologic therapy. Calcium channel blockers inhibit cellular uptake of calcium, and because intracellular calcium is necessary for lower esophageal sphincter contraction, relaxation occurs. Calcium channel blockers have been evaluated in the long-term treatment of achalasia, but the use of these drugs often induces tolerance, which severely diminishes the effects over the time. Nifedipine has been shown to induce long-term remission and even normalization of physiology in a minority of patients. Verapamil has been shown to decrease lower esophageal sphincter pressure, but did not demonstrate a relevant symptomatic improvement. ${ }^{20-23}$

Nitrate therapy acts by counteracting the decrease in the inhibitory neurotransmitter, nitric oxide. This leads to a decrease in lower esophageal sphincter tone, with a subsequent decrease in lower esophageal sphincter pressure. Sublingual isosorbide dinitrate has been shown to decrease the basal lower esophageal sphincter pressure and to improve esophageal emptying. ${ }^{24} \mathrm{~A}$ recent meta-analysis regarding the use of nitrates in the treatment of achalasia have found too low a number of controlled studies, with heterogeneous data, and considerable reported side effects, so was unable to recommend clinical use of these drugs for the disease. ${ }^{25}$ Because side effects are more profound with nitrates, calcium channel

Table I Current therapeutic options for achalasia

\begin{tabular}{|c|c|c|}
\hline Therapeutic modality & Mode of action & Adverse effects \\
\hline \multicolumn{3}{|l|}{ Pharmacologic therapy } \\
\hline$>$ Nitrates (isosorbide) & Inhibition of muscle contraction, & Hypotension, headache, drowsiness \\
\hline $\begin{array}{l}\text { Calcium channel blockers (nifedipine, } \\
\text { verapamil) }\end{array}$ & $\begin{array}{l}\text { induction of relaxation, promotes } \\
\text { esophageal emptying }\end{array}$ & \\
\hline$>$ 5-phosphodiesterase inhibitors (sildenafil) & $\begin{array}{l}\text { Induction of NO release, reduction } \\
\text { of LES pressure }\end{array}$ & Hypertension, angina \\
\hline \multicolumn{3}{|l|}{ Endoscopic therapies } \\
\hline $\begin{array}{l}>\text { Botulinum toxin (injection into } \\
\text { the muscular layer of LES) } \\
>\text { Pneumatic dilation of the hypertonic LES }\end{array}$ & $\begin{array}{l}\text { Potent inhibition of the release of acetylcholine, } \\
\text { improves passive esophageal emptying } \\
\text { Aims at fracturing the fibers of the } \\
\text { muscularis propria }\end{array}$ & $\begin{array}{l}\text { Feasible and safe on an outpatient basis; } \\
\text { Heller myotomy could be more difficult in } \\
\text { patients that underwent repeated injections } \\
\text { Esophageal perforation or rupture, bleeding, } \\
\text { local pain } \\
\text { Gastroesophageal reflux }\end{array}$ \\
\hline \multicolumn{3}{|l|}{ Surgery } \\
\hline $\begin{array}{l}>\text { Laparoscopic Heller myotomy } \\
\text { plus antireflux fundoplication }\end{array}$ & $\begin{array}{l}\text { Deep disruption of muscular hypertonic } \\
\text { fibers in the LES }\end{array}$ & $\begin{array}{l}\text { Although the most "pathophysiologic" } \\
\text { solution, is costly; possible postoperative } \\
\text { complications } \\
\text { Gastroesophageal chronic reflux and Barrett's }\end{array}$ \\
\hline $\begin{array}{l}\text { Esophagogastrectomy with gastric } \\
\text { or colonic interposition }\end{array}$ & $\begin{array}{l}\text { Total modification of the LES anatomy; } \\
\text { to be left for end-stage illness }\end{array}$ & Very invasive, possible severe complications \\
\hline
\end{tabular}

Abbreviations: LES, lower esophageal sphincter; NO, nitric oxide. 
blockers are still more widely used. Table 2 summarizes the data and the results of chronic prospective and controlled studies involving the use of calcium channel blockers and nitrates in achalasia.

Sildenafil, a 5-phosphodiesterase inhibitor that reduces the breakdown of cyclic GMP, the second messenger mediating nitric oxide-induced relaxation, has been proposed as an alternative pharmacologic agent for the treatment of achalasia. Experimental data demonstrate its ability to decrease lower esophageal sphincter tone and residual pressure. ${ }^{26}$ Further studies are needed to determine whether this might be of clinical utility in achalasia.

Although a clinical guideline for the management of achalasia is still not available, we can assume that pharmacologic therapies presently have very limited value in its treatment. However, the use of sublingual nifedipine before meals seems to remain solely indicated for patients not willing or unable to undergo any other procedure and/or waiting for a more definitive therapy, or as supportive treatment for refractory chest pain.

\section{Endoscopic therapies}

To date, the primary modality of endoscopic therapy for achalasia is the injection of botulinum toxin $\mathrm{A}$ into the lower esophageal sphincter. Botulinum toxin $\mathrm{A}$ is a potent inhibitor of the release of acetylcholine, which has an excitatory influence on lower esophageal sphincter tone. Injection of botulinum toxin A into the lower esophageal sphincter improves "passive" esophageal emptying by counterbalancing the selective loss of inhibitory neurons in the myenteric plexus, decreasing lower esophageal sphincter pressure, and increasing lower esophageal sphincter opening when compared with injection of placebo. ${ }^{27,28}$

The mean duration of effect of a single injection of botulinum toxin A is $10-12$ months, with a wide variability ranging from three months to three years. The reason for such variability is unknown, but is probably related to another drawback of the toxin, ie, the development of an autoimmune response with the production of antibodies that may, in turn, decrease its efficacy in some patients.

Botulinum toxin A 80-100 U is injected through a $5 \mathrm{~mm}$ needle into the lower esophageal sphincter, with aliquots of 20-25 $U$ of the toxin injected into the four quadrants of the lower esophageal sphincter. The procedure is no more demanding than a routine endoscopy, and apart from occasional complaints of transient chest pain, patients tolerate it very well. They can go home after they recover from sedation and are allowed to eat soft foods later in the day. Symptomatic improvement occurs gradually and usually peaks 1-3 days later, although this may be delayed even further in the occasional patient.

Following a single treatment with botulinum toxin A, relief of symptoms has been reported in almost $80 \%$ of patients. After six months, $50 \%$ of patients may remain in remission, while others will need repeated injections, or other treatment options, such as pneumatic dilation or surgical myotomy.

Annese $^{28}$ reported a success rate of $68 \%$ at 24 months after repeated administration of botulinum toxin A injection, while Pasricha ${ }^{29}$ found a $30 \%$ efficacy rate after a mean follow-up of two years. Injection of botulinum toxin A seems to be simple and safe, without carrying any risk of perforation. ${ }^{30}$ Post-treatment evaluations have revealed that neither pretreatment lower esophageal sphincter pressure, amplitude of esophageal contractions, nor duration of illness could be used to predict the outcome of botulinum toxin $\mathrm{A}$ injection. Instead, young age and male gender were found to affect the outcome adversely.

Surgeons have reported that Heller myotomy could be more difficult in patients who undergo repeated botulinum toxin A injection, due to increased adhesion of the muscular layer, but, so far, this therapeutic option has to be chosen as a first step in all patients who are eligible for it. ${ }^{31}$ In contrast, botulinum toxin $\mathrm{A}$ is widely demonstrated to be the most

Table 2 Clinical studies with calcium channel blockers and nitrates in achalasia

\begin{tabular}{|c|c|c|c|c|}
\hline Author & Drug & Patients (n) & Efficacy (\%) & Follow-up (months) \\
\hline Gelfonc 1981 & Isosorbide & 24 & 79 & $2-19$ \\
\hline Silverstein 1982 & Diltiazem & 8 & 50 & 6 \\
\hline Gelfonc 1982 & Nifedipine & 15 & 53 & $8-18$ \\
\hline Bortolotti et al ${ }^{19}$ & Nifedipine & 20 & 90 & $6-18$ \\
\hline Traube 1992 & Nifedipine & 14 & $65-80$ & 6 \\
\hline Coccia 1992 & Nifedipine & 14 & 77 & 21 \\
\hline Triadafilopoulos et $\mathrm{a}^{20}$ & Nifedipine & 14 & NA & 10 \\
\hline Triadafilopoulos et $\mathrm{a}^{20}$ & Verapamil & 14 & NA & 10 \\
\hline
\end{tabular}

Abbreviation: NA, not available. 
effective treatment option in elderly patients or in patients with comorbid illnesses, in whom dilatation or surgery is high-risk. ${ }^{32}$ Symptom relief was found to last up to 1-2 years with a single injection in the elderly.

Historically, pneumatic dilation was the first attempt at therapy in esophageal achalasia, and was described in 1674 by Sir Thomas Willis. ${ }^{32}$ Pneumatic dilation of the lower esophageal sphincter in patients with achalasia aims at fracturing the fibers of the muscularis propria. Bougienage or a "standard" balloon for dilation are typically ineffective, but pneumatic dilation with a rigid and high-sized balloon across the lower esophageal sphincter has been shown to be effective and quite inexpensive. Forceful dilatation of the lower esophageal sphincter is considered to date the most effective nonsurgical treatment for achalasia, although details of the procedure vary in different institutions. While there is no clear consensus on the technical details of balloon dilatation, most leading operators used their own pneumatic dilatation technique passed along from experienced to junior physicians. Inpatient versus ambulatory treatment, sedated versus nonsedated dilation, the sedative used, the dilator system, initial balloon size, speed, pressure, duration, number of dilations per endoscopic session, and timing of redilations differ from center to center. ${ }^{34-37}$

Typically, pneumatic dilation is performed over a guide wire under fluoroscopic guidance. This allows for assessment of the progress of dilation as the narrowed "waist" of the lower esophageal sphincter disappears. However, in addition to radiation exposure, this requires bulky and expensive fluoroscopy equipment, which may be in high demand or not available for general use. Performing pneumatic dilation under direct endoscopic visualization is a good alternative to fluoroscopic guidance. After placement of the dilator over the guide wire, the endoscope is reinserted into the esophagus. The balloon placement and dilation effects are observed proximal to the balloon. This method has been performed for more than 20 years, ${ }^{38}$ and the American Society of Gastrointestinal Endoscopy has suggested that either visualization method is acceptable for safe dilation in achalasia. ${ }^{39}$ Major complications are rare after pneumatic dilation. The most serious complication is esophageal perforation, which occurs at a mean rate of about $2.5 \%{ }^{40}$ Gastroesophageal reflux is the most frequent chronic complication after lower esophageal sphincter dilation for achalasia. With 24-hour $\mathrm{pH}$ monitoring and esophageal manometry, it is possible to define the pathophysiologic subset of the reflux, because it is nearly always associated with a hypotensive lower esophageal sphincter and ineffective esophageal body motility. ${ }^{41}$
Some investigators debate the role of botulinum toxin A injection versus pneumatic dilation. A recent Cochrane review of six randomized controlled trials including 178 patients evaluated symptom recurrence after esophageal dilation versus endoscopic botulinum toxin A injection at one, six, and 12 months after treatment. Thirty percent of patients undergoing dilation experienced symptom recurrence and treatment failure at 12 months versus $74 \%$ of patients who received botulinum toxin $\mathrm{A} .{ }^{42}$ Furthermore, a systematic review and meta-analysis of 105 papers that reported on 761 patients with achalasia who underwent endoscopic treatment with esophageal dilation or botulinum toxin A showed that symptom relief was better for dilation, and the necessity for further treatment was significantly reduced. ${ }^{43}$

\section{Surgery}

Minimally invasive surgical techniques have dramatically modified the management algorithm of the treatment of achalasia. The advantage of a less invasive, safe, and effective surgical option prompts gastroenterologists to choose patients earlier for surgery, because this obviates the need for dilation. ${ }^{44,45}$

Currently, the standard surgical management for achalasia is the laparoscopic Heller myotomy, first reported in 1991. ${ }^{46}$ This technique is associated with the greater decrease in dysphagia, a shorter hospital stay, lower risk of postoperative gastroesophageal reflux, and low complication rates. ${ }^{47}$ An antireflux procedure can further reduce postoperative heartburn rates by $80 \%$, as well as the risk of esophagitis and peptic stricture. A Dor or Toupet fundoplication reduces reflux as well as a Nissen procedure, but the partial wraps trend toward less dysphagia. The dysphagia rate attributed to fundoplication ranges from $0 \%$ to $8 \%$. Failure of improvement with dilatation suggests incomplete myotomy and a requirement for repeat manometry. Optimal length of the cardiomyotomy is at least $2 \mathrm{~cm}$. Although a Dor fundoplication is more commonly reported, the choice of Toupet versus Dor depends on surgeon preference. ${ }^{48}$ There are very few randomized prospective trials examining esophagomyotomy versus pneumatic dilation. ${ }^{49}$ One study showed equivalent effectiveness at relieving symptoms initially, but at follow-up it showed those patients who had esophagomyotomy had fewer recurrent symptoms than those who had pneumatic dilation. Very recent preliminary data from a large and powerful multicenter randomized clinical trial comparing the treatment success of these two different therapies suggest that, after two years of follow-up, pneumatic dilation and laparoscopic myotomy have a comparable success rate 
of $87 \%-92 \% .{ }^{50}$ Some studies suggest that pneumatic dilation may achieve long-term relief of symptoms in patients older than 50 years. ${ }^{51}$

Despite symptom improvement by either pneumatic dilation or surgical myotomy in achalasia patients, $10 \%-15 \%$ of those so treated will present with progressive deterioration in their esophageal function, and up to $5 \%$ may eventually require an esophagectomy. The optimal reconstruction for the resected esophagus should be gastric interposition, colon interposition, and jejunal interposition, all of which have their respective advantages and disadvantages. ${ }^{52,53}$ It is questionable if progression to esophageal cancer following Heller myotomy (adenocarcinoma in Barrett's esophagus or squamous cell carcinoma) is a failure of surgery or a failure of follow-up. Development of adenocarcinoma after myotomy in the sequelae of Barrett's esophagus might be due to a too long myotomy, and only few case reports on this association are available. ${ }^{54}$

\section{Nutritional approach}

The management of the patient with achalasia and nutritional problems is very similar to that of patients with dysphagia due to neurologic disease or esophagogastric cancer. ${ }^{55,56}$ Oral feeding has relevant psychosocial significance to patients and their families, and should be continued whenever possible. In some patients, oral intake is often not adequate even in the absence of significant swallowing difficulties. In mild to moderate achalasia, nutrition is generally mildly affected and, if the family encourages the patient to follow dietary modifications, loss of weight and malnutrition rarely occurs.

Dysphagia diets should be highly individualized, including modification of food texture or fluid viscosity. Food may be chopped, minced, or puréed, and fluids may be thickened. ${ }^{57}$

If a patient is unable to eat or drink or to consume sufficient quantities of food, or the risk of pulmonary aspiration is high, tube feeding should be provided. If there is a possibility for surgical myotomy, enteral nutrition via a nasal feeding tube will be adequate as a provisional measure, considering that a malnourished patient is always at major risk for postoperative complications. In very rare and selected cases of end-stage achalasia, in which there is any further possibility of surgery or pneumatic dilation, the insertion of the feeding tube through a percutaneous radiologic gastrostomy rather than a surgical gastrostomy would be the treatment of choice. Percutaneous gastric tube feeding is effective and usually acceptable to patients and their carers. Long-term complications include tube obstruction and wound infection. In some patients who are fed via a gastric tube, pulmonary aspiration may occur and routine intrajejunal feeding has been suggested for these cases. ${ }^{58}$

\section{Possible future therapies}

The utility of self-expanding $30 \mathrm{~mm}$ endoscopic metallic stents for achalasia has been prospectively evaluated in 75 patients at a single center over a 13 -year period. The clinical success rate after 10 years of follow-up after the stent was removed was high (83\%). There were no perforations or mortality associated with the treatment, but stent migration occurred in 5\% of patients, reflux in $20 \%$, and chest pain in $38.7 \% .^{59}$

Pasricha reported a method of submucosal endoscopic myotomy with no skin incision in an experimental model. ${ }^{59}$ More recently, Inoue described a clinical application of modified Pasricha technique as per oral endoscopic myotomy (POEM) to provide a less invasive permanent treatment for esophageal achalasia. ${ }^{60}$ Thirty-five achalasia patients who had lasting symptoms of dysphagia received POEM. ${ }^{61}$ Barium swallows before and after the procedure demonstrated total release of thickened lower esophageal sphincter. Mean operating time was about 120 minutes and the mean hospital stay after the procedure was 4.9 days. No severe complication was reported and dysphagia symptoms disappeared after the procedure. Mean resting pressure of the sphincter fell. Subjective symptom score was significantly improved in all cases. This method is achieved with the already available techniques and devices for routine endoscopic myotomy. This procedure allows a direct approach to the thickened inner muscular layer with no skin incision and effectively releases lower esophageal sphincter pressure. Myotomy length can be flexibly determined according to the patients' symptoms, such as dysphagia and chest pain. This seems to be a very promising technique possibly leading to a new frontier for endotherapy of achalasia, but further studies of the long-term efficacy and a comparison of POEM with other interventional therapies are awaited. ${ }^{62}$

In view of the fact that the enteric neurons innervating the esophagus and the lower esophageal sphincter could disappear due to an autoimmune mechanism, immunosuppressive therapy could prevent disease progression. ${ }^{63}$ However, at the time of diagnosis, the number of neurons has already decreased, leading to significant dysfunction and symptoms. Although this approach may theoretically prevent further disappearance of neurons, it is possible that comes too late and will fail to restore function. 
Recent experimental studies in mice suggest that transplantation of neuronal stem cells might be a future therapeutic option. Indeed, neuronal stem cells injected in the pylorus survived and even expressed nitric oxide synthase. ${ }^{64}$ The advantage of such a technique would be that not only would sphincter function be restored, but perhaps even peristalsis too. That is a very suggestive hypothesis, and clearly a lot of research remains to be done further exploring this approach.

\section{Decision-making and cost-effectiveness}

The appropriate treatment for any given patient with achalasia depends on their willingness to undergo invasive procedures and on their physical ability to endure them. A decision analysis model has been developed for the treatment of achalasia. Four therapeutic options were evaluated, ie, laparoscopic Heller myotomy and partial fundoplication, pneumatic dilation, botulinum toxin injection, and thoracoscopic Heller myotomy. Based on complications, need for repeated procedures, and overall treatment cost, it has been found that laparoscopic Heller myotomy with fundoplication was the preferred treatment strategy. ${ }^{65}$ The authors recommended that those patients who meet diagnostic criteria for achalasia (manometric, endoscopic, radiographic) in a referral center and who are good surgical candidates should be referred to an experienced surgeon for minimally invasive modified Heller myotomy. Patients who are not good surgical candidates and cannot accept the risk of pneumatic dilation can be treated with single-shot or repeated botulinum toxin A injection or can be treated with pharmacological agents.

Several cost analyses have been performed to verify which modality of treatment is the most cost-effective. Multiple studies evaluating the cost of the initial 5-10 years of therapy have demonstrated that pneumatic dilatation is the most cost-effective modality in otherwise healthy populations. ${ }^{66}$ In patients with other comorbidities that decrease life expectancy, botulinum toxin A is more cost-effective. ${ }^{67}$ Although surgery seems to be the most definitive and effective treatment for achalasia, it appears to be costly over the initial years of therapy.

\section{Summary}

Although the ultimate goal of the treatment of esophageal achalasia should be the restoration of esophageal peristalsis and lower esophageal sphincter relaxation, at present there is not a known therapeutic option addressing this goal, and both gastroenterologists and surgeons continue to destroy the lower esophageal sphincter. Whereas medical therapy has poor, if any, results, Heller myotomy and pneumatic dilatation are successful in 70\%-90\% of patients in the first year, but the success rate slowly declines with time. Botulinum toxin injection in the lower esophageal sphincter is safe and effective, but it has to be reserved for elderly patients with comorbid illnesses. Pneumatic dilation or Heller myotomy seems to be the best solution, each modality having technical problems and possible complications. Which of these treatments might be the therapy of choice for achalasia in particular subgroups of patients remains to be investigated. Clearly, more research is required to develop therapies to restore the functional anatomy of the lower esophageal sphincter.

\section{Disclosure}

The authors report no conflicts of interest in this work.

\section{References}

1. Park W, Vaezi MF. Etiology and pathogenesis of achalasia: The current understanding. Am J Gastroenterol. 2005;100:1404-1404.

2. Zarate N, Mearin F, Gil-Vernet JM, et al. Achalasia and Down's syndrome: Coincidental association or something else? Am J Gastroenterol. 1999;94:1674-1677.

3. Wong RK, Maydonovitch CL, Metz SJ, Baker JR Jr. Significant DQw1 association in achalasia. Dig Dis Sci. 1989;34:349-352.

4. Ruiz-de-Leon A, Mendoza J, Sevilla-Mantilla C, et al. Myenteric antiplexus antibodies and class II HLA in achalasia. Dig Dis Sci. 2002;47:15-19.

5. Robertson CS, Martin BA, Atkinson M. Varicella-zoster virus DNA in the esophageal myenteric plexus in achalasia. Gut. 1993;34: 299-302.

6. Verne GN, Sallustio JE, Eaker EY. Anti-myenteric neuronal antibodies in patients with achalasia. A prospective study. Dig Dis Sci. 1997;42: 307-313.

7. Gockel I, Eckardt VF, Schmitt T, Junginger T. Pseudoachalasia: A case series and analysis of the literature. Scand J Gastroenterol. 2005;40: 378-385.

8. Poh DL, Tutuian R. 2007. Achalasia: An overview of diagnosis and treatment. J Gastrointestin Liver Dis. 2007;4:297-303.

9. Spechler N, Castell D. Classification of esophageal motility abnormalities. Gut. 2001;49:145-151.

10. Aggestrup S, Uddman R, Sundler F, et al. Lack of vasoactive intestinal polypeptide nerves in esophageal achalasia. Gastroenterology. 1983;84: 924-927.

11. Hirano I. Pathophysiology of achalasia and diffuse esophageal spasm. GI Motility Online. 2006. doi:10.1038/gimo22.

12. Kraichelyn RE, Farrugia G. Achalasia: Physiology and etiopathogenesis. Dis Esophagus. 2006;19:213-223.

13. Faussone-Pellegrini MS, Cortesini C. Ultrastructural features and localization of the interstitial cells of Cajal in the smooth muscle coat of human esophagus. J Submicrosc Cytol. 1985;17:187-197.

14. Szurszewski JH, Farrugia G. Carbon monoxide is an endogenous hyperpolarizing factor in the gastrointestinal tract. Neurogastroenterol Motil. 2004;16:81-85.

15. Fox EA, Phillips RJ, Martinson FA, Baronowsky EA, Powley TL. C-Kit mutant mice have a selective loss of vagal intramuscular mechanoreceptors in the forestomach. Anat Embryol. 2001;204:11-26. 
16. Ward SM, Morris G, Reese L, Wang XY, Sanders KM. Interstitial cells of Cajal mediate enteric inhibitory neurotransmission in the lower esophageal and pyloric sphincters. Gastroenterology. 1998;115: 314-329.

17. Zarate N, Wang XY, Tougas G, et al. Intramuscular interstitial cells of Cajal associated with mast cells survive nitrergic nerves in achalasia. Neurogastroenterol Motil. 2006;18:556-568.

18. Huizinga JD, Zarate N, Farrugia G. Physiology, injury, and recovery of interstitial cells of Cajal: Basic and clinical science. Gastroenterology. 2009;137:1548-1556.

19. Bortolotti M, Labo G. Clinical and manometric effects of nifedipine in patients with esophageal achalasia. Gastroenterology. 1981;80:39-44.

20. Triadafilopoulos G, Aaronson M, Sackel S, Burakoff R. Medical treatment of esophageal achalasia. Double-blind crossover study with oral nifedipine, verapamil and placebo. Dig Dis Sci. 1991;36:260-267.

21. Traube M, Dubovik S, Lange RC, McCallum RW. The role of nifedipine therapy in achalasia: Results of a randomized, double blind, placebocontrolled study. Am J Gastroenterol. 1989;84:1259-1262.

22. Bortolotti M. Medical therapy of achalasia: A benefit reserved for few. Digestion. 1999;60:11-16.

23. Bortolotti M, Coccia G, Brunelli F, et al. Isosorbide dinitrate or nifedipine: Which is preferable in the medical therapy of achalasia? Ital J Gastroenterol. 1994;26:379-382.

24. Wen ZH, Gardener E, Wang YP. Nitrates for achalasia. Cochrane Database Syst Rev. 2004:CD002299.

25. Bortolotti M, Mari C, Lopilato C, Porrazzo G, Miglioli M. Effects of sildenafil on esophageal motility of patients with idiopathic achalasia. Gastroenterology. 2000;118:253-257.

26. Pasricha PJ, Ravich WJ, Hendrix TR, Sostre S, Jones B, Kalloo AN. Intrasphincteric botulinum toxin for the treatment of achalasia. $N$ Engl J Med. 1995;332:774-778.

27. Annese V, Bassotti G. Non-surgical treatment of esophageal achalasia. World J Gastroenterol. 2006;12:5763-5766.

28. Annese V, Bassotti G, Coccia G, et al. Multicenter randomised study of intrasphincteric botulinum toxin in patients with esophageal achalasia. GISMAD Achalasia Study Group. Gut. 2000;46:597-600.

29. Pasricha PJ, Rai R, Ravich WJ, Hendrix TR, Kalloo AN. Botulinum toxin for achalasia: Long-term outcome and predictors of response. Gastroenterology. 1996;110:1410-1415.

30. Pehlivanov N, Pasricha PJ. Achalasia: Botox, dilatation or laparoscopic surgery in 2006. Neurogastroenterol Motil. 2006;18:799-804.

31. Dughera L, Battaglia E, Maggio D, et al. Botulinum toxin treatment of esophageal achalasia in the old old and oldest old: A 1-year follow-up study. Drugs Aging. 2005;22:779-783.

32. Willis T. Pharmaceutice Rationalis Sive Diatriba do Medicamentorum Operationibus in Humano Corpore. London: Hagea Comitis, 1674.

33. Mikaeli J, Bishehsari F, Montazeri G, Yaghoobi M, Malekzadeh R. Pneumatic balloon dilatation in achalasia: A prospective comparison of safety and efficacy with different balloon diameters. Aliment Pharmacol Ther. 2004;20:431-436.

34. Kadakia SC, Wong RK. Graded pneumatic dilation using Rigiflex achalasia dilators in patients with primary esophageal achalasia. Am J Gastroenterol. 1993;88:34-38.

35. Wong RK. Pneumatic dilation for achalasia. Am J Gastroenterol. 2004;99:578-580.

36. Zerbib F, Thetiot V, Richy F, Benajah DA, Message L, Lamouliatte H. Repeated pneumatic dilations as long-term maintenance therapy for esophageal achalasia. Am J Gastroenterol. 2006;101:692-697.

37. Levine ML, Dorf BS, Moskowitz G, Bank S. Pneumatic dilatation in achalasia under endoscopic guidance: Correlation pre- and postdilatation by radionuclide scintiscan. Am J Gastroenterol. 1987;82:311-314.

38. American Society for Gastrointestinal Endoscopy. Esophageal dilation. Gastrointest Endosc. 1998;48:702-704.

39. Moawad FJ, Wong RK. Modern management of achalasia. Curr Opin Gastroenterol. 2010;26:384-388.
40. Novais PA, Lemme EM. 24-h pH monitoring patterns and clinical response after achalasia treatment with pneumatic dilation or laparoscopic Heller myotomy. Aliment Pharmacol Ther. 2010;32: 1257-1265.

41. Leyden JE, Moss AC, MacMathuna P. Endoscopic pneumatic dilation versus botulinum toxin injection in the management of primary achalasia. Cochrane Database Syst Rev. 2006:CD005046.

42. Wang L, Li YM, Li L. Meta-analysis of randomized and controlled treatment trials for achalasia. Dig Dis Sci. 2009;54:2303-2301.

43. Patti MG, Fisichella PM, Perretta $S$, et al. Impact of minimally invasive surgery on the treatment of esophageal achalasia: A decade of change. J Am Coll Surg. 2003;196:698-703.

44. Ishaq S. Treatment of achalasia: The role of laparoscopic cardiomyotomy needs to be emphasized. Am J Gastroenterol. 2004;99:2278-2279.

45. Mineo TC, Ambrogi V. Long-term results and quality of life after surgery for esophageal achalasia: One surgeon's experience. Eur J Cardiothorac Surg. 2004;25:1089-1096.

46. Finley RJ, Clifton JC, Stewart KC, Graham AJ, Worsley DF. Laparoscopic Heller myotomy improves esophageal emptying and the symptoms of achalasia. Arch Surg. 2001;136:892-896.

47. Litle VR. Laparoscopic Heller myotomy for achalasia: A review of the controversies. Ann Thorac Surg. 2008;85 Suppl 7:43-46.

48. Csendes A, Braghetto I, Henriquez A, et al. Late results of a prospective randomised study comparing forceful dilatation and oesophagomyotomy in patients with achalasia. Gut. 1989;30:299-304.

49. Boeckxstaens GE, Annese V, Bruley des Varannes S, et al. The European achalasia trial: A randomized multi-centre trial comparing endoscopic pneumodilation and laparoscopic Heller myotomy as primary treatment of idiopathic achalasia. Gut. 2010;59 Supp1 III:A25.

50. Vela MF, Richter JE, Khandwala F, et al. The long-term efficacy of pneumatic dilatation and Heller myotomy for the treatment of achalasia. Clin Gastroenterol Hepatol. 2006;4:580-587.

51. Duranceau A, Liberman M, Martin J, Ferraro P. End-stage achalasia. Dis Esophagus. Decemeber 17, 2010. [Epub ahead of print].

52. Hsu HS, Wang CY, Hsieh CC, Huang MH. Short-segment colon interposition for end-stage achalasia. Ann Thorac Surg. 2003;76:1706-1710.

53. Gockel I, Timm S, Sgourakis GG, Musholt TJ, Rink AD, Lang H. Achalasia - if surgical treatment fails: Analysis of remedial surgery. $J$ Gastrointest Surg. 2010;14 Suppl 1:S46-S57.

54. Foley N, Teasell R, Salter K, Kruger E, Martino R. Dysphagia treatment post stroke: A systematic review of randomised controlled trials. Age Ageing. 2008;37:258-264.

55. Bower MR, Martin RC 2nd. Nutritional management during neoadjuvant therapy for esophageal cancer. J Surg Oncol. 2009;100:82-87.

56. Pardoe EM. Development of a multistage diet for dysphagia. J Am Diet Assoc. 1993;93:568-571.

57. Given MF, Hanson JJ, Lee MJ. Interventional radiology techniques for provision of enteral feeding. Cardiovasc Intervent Radiol. 2005;28: 692-703.

58. Zhao JG, Li YD, Cheng YS, et al. Long-term safety and outcome of a temporary self-expanding metallic stent for achalasia: A prospective study with a 13-year single-center experience. Eur Radiol. 2009;19: 1973-1980.

59. Pasricha PJ, Hawari R, Ahmed I, et al. Submucosal endoscopic esophageal myotomy: A novel experimental approach for the treatment of achalasia. Endoscopy. 2007;39:761-764.

60. Inoue H, Minami H, Kobayashi Y, et al. Peroral endoscopic myotomy (POEM) for esophageal achalasia. Endoscopy. 2009;42:265-271.

61. Minami H, Inoue H, Hosoya T, et al. Per-oral endoscopic myotomy: POEM - 35 cases clinical experiences - noble endoscopic treatment against esophageal achalasia. Gut. 2010;59 Suppl III:A2 .

62. De Giorgio R, Guerrini S, Barbara G, et al. Inflammatory neuropathies of the enteric nervous system. Gastroenterology. 2004;126:1872-1873.

63. Micci MA, Learish RD, Li H, et al. Neural stem cells express RET, produce nitric oxide, and survive transplantation in the gastrointestinal tract. Gastroenterology. 2001;121:757-766. 
64. Urbach DR, Hansen PD, Khajanchee YS, et al. A decision analysis of the optimal initial approach to achalasia: Laparoscopic Heller myotomy with partial fundoplication, thoracoscopic Heller myotomy, pneumatic dilatation, or botulinum toxin injection. J Gastrointest Surg. 2001;5:192-205

65. O'Connor JB, Singer ME, Imperiale TF, Vaezi MF, Richter JE. The cost-effectiveness of treatment strategies for achalasia. Dig Dis Sci. 2002;47:1516-1525.
66. Panaccione R, Gregor JC, Reynolds RP, Preiksaitis HG. Intrasphincteric botulinum toxin vs pneumatic dilatation for achalasia: A cost minimization analysis. Gastrointest Endosc. 1999;50:492-498.

67. Zayat EN, Schuster MM. Nitric oxide - a major player in esophageal motility. Am J Gastroenterol. 2000;95:1584-1585.

Clinical and Experimental Gastroenterology

\section{Publish your work in this journal}

Clinical and Experimental Gastroenterology is an international, peerreviewed, open access journal, publishing all aspects of gastroenterology in the clinic and laboratory, including: Pathology, pathophysiology of gastrointestinal disease; Investigation and treatment of gastointestinal disease; Pharmacology of drugs used in the alimentary tract;
Immunology/genetics/genomics related to gastrointestinal disease. This journal is indexed on CAS. The manuscript management system is completely online and includes a very quick and fair peer-review system. Visit http://www.dovepress.com/testimonials.php to read real quotes from published authors.

Submit your manuscript here: http://www.dovepress.com/clinical-and-experimental-gastroenterology-journal 